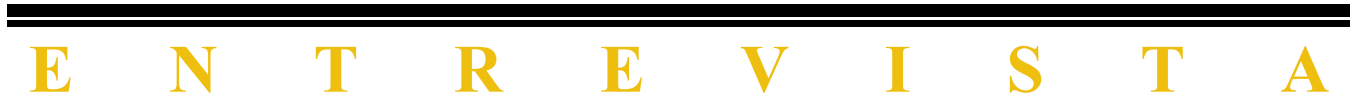




\section{ENTREVISTA A \\ GEORG HENRIK VON WRIGHT}

1. Tu obra, y especialmente Norma y Acción, ha ejercido una gran influencia en la filosofía del derecho en los últimos 25 años. ¿Cuáles han sido tus contactos con la filosofia del derecho antes de haber escrito Norma y Acción?

-Mi contacto con la filosofía del derecho fue establecido en una época relativamente tardía, después de haber «descubierto» la lógica deóntica y haber notado que el descubrimiento atrajo también la atención de los teóricos del derecho. Después de mi regreso de Cambridge a Helsinki en 1952 he participado por algunos años en un círculo de discusión, llamado Theoria Juris, que fue fundado por Otto Brusiin.

El primero, y por mucho tiempo el único, filósofo del derecho, cuya obra había conocido, era Hans Kelsen. He llegado a admirar su obra sobre la teoría del derecho y del estado -y me sentí muy contento de tener la oportunidad de encontrarme con él durante su visita a Finlandia en 1952. Él ya estaba familiarizado con mi obra sobre la lógica deóntica y pensaba que ésta apoyaba algunas de sus propias ideas referentes a «contradicciones» y «lagunas» en el derecho. Presumiblemente, Kelsen cambió más tarde sus opiniones respecto de la relevancia de la lógica (deóntica) para la teoría jurídica.

2. ¿De qué manera las reacciones de los filósofos del derecho a Norma y Acción y a tus artículos sobre la lógica deóntica han influenciado tu propio pensamiento?

-Mis propias ideas sobre la lógica deóntica ciertamente han sufrido muchos cambios desde el nacimiento de esta temática hace unos cuarenta años. Pero estos cambios sólo han sido causados en mínima medida por lo que han escrito otros, sea críticamente, sea con espíritu positivo. El desarrollo de mis pensamientos ha surgido de una necesidad interior de reflexionar sobre los fundamentos conceptuales y presuposiciones de la materia. Pienso que puedo decir honestamente que los únicos autores que han 
estimulado y hasta cierto punto influenciado mis pensamientos son Carlos Alchourrón y tú. Las observaciones de Alchourrón y tuyas sobre cuestiones de fundamentación -tales como, por ejemplo, la distinción entre normas y proposiciones normativas- resultaron para mí filosóficamente desafiantes. Y algunas de vuestras contribuciones constructivas -por ejemplo, aquellas referidas a la lógica de la derogación- han abierto nuevos rumbos también para mí en el desarrollo técnico de esta nueva rama de la lógica.

3. ¿Cuáles en tu opinión la importancia de la lógica deóntica para la filosofía del derecho?

-Sobre esta cuestión no tengo una opinión definida. La razón es que soy demasiado ignorante de la teoría jurídica, a pesar de las lecturas de Kelsen y Hart y más tarde también de Aarnio, Dworkin, Perelman y otros. Entiendo que la cuestión es problemática. Implícitamente, sin embargo, estoy convencido de que la lógica deóntica es importante para todo intento de comprender la estructura conceptual de los órdenes jurídicos. Pero estoy dispuesto a conceder que puede haber distintos enfoques para la comprensión del derecho para los cuales la lógica deóntica es menos útil. Por ejemplo, la hermenéutica de los textos jurídicos y el estudio de la argumentación jurídica.

4. Desde que escribiste hace ya cuarenta años tu primer artículo sobre la lógica deóntica, se ha publicado sobre este tema una gran cantidad de libros y artículos, por filósofos y lógicos. ¿Qué piensas hoy sobre esta rama de la lógica? ¿Cuáles son sus principales logros y defectos? ¿Cuáles son los principales problemas en este campo que no han sido solucionados hasta ahora?

-Ha sido una sorpresa para mí que la lógica deóntica haya atraído tanta atención por parte de los lógicos y de los teóricos del derecho. (El número de trabajos publicados sobre el tema excede hoy de 2000 -sin contar a los precursores en el período de preguerra o en la tradición escolástica de la Edad Media). Una razón para ello, estoy seguro, ha sido el hecho de que la lógica deóntica resultara más interesante como lógica- y también más problemática- de lo que se podía esperar.

Entre los hitos en el desarrollo formal de esta disciplina en los últimos cuarenta años, para mencionar unos pocos, están el intento de Alan Anderson de «reducir» la lógica deóntica a la lógica modal ordinaria (y las discusiones a que dio lugar); el descubrimiento de Alchourrón y tuyo de la lógica de la derogación de normas y su tratamiento; quizá también mis propios esfuerzos, seguidos por otros, de basar la lógica deóntica en una teoría formal de la acción humana y de los cambios en la naturaleza. En época reciente hay también un interés creciente en las aplicaciones 
de la lógica deóntica al estudio de la inteligencia artificial y el desarrollo de los llamados sistemas expertos.

5. Has cambiado varias veces en el transcurso de los años tu posición respecto de la interpretación de la lógica deóntica. La has considerado sucesivamente como una lógica de normas o como una lógica de las proposiciones normativas, esto es, de las proposiciones acerca de (la existencia de) las normas, o como una "quasi lógica» de la legislación racional. ¿Cuál es tu posición ahora? ¿Piensas que a pesar del hecho de que las normas carecen de valores de verdad una genuina lógica de normas es, después de todo, posible?

-Originariamente, pensé que la lógica deóntica no era más que otro vástago de la lógica modal que en aquel entonces estaba en proceso de renacimiento. Sólo unos diez años más tarde me di cuenta plenamente de que este vástago ofrecía no sólo inspiración para el lógico, sino también serios problemas para el filósofo. Lo que convierte a la lógica deóntica en problemática es el hecho de que, conforme a un punto de vista corriente y pienso que básicamente correcto, las normas carecen de valores de verdad, no son ni verdaderas ni falsas. Pero si esto es así, ¿de qué manera se puede hablar de una «lógica» de normas, de relaciones tales como contradicción y consecuencia entre normas? ¿O tal vez la lógica deóntica no sea «realmente» una lógica de normas, sino de algunas entidades relacionadas («proposiciones normativas») que son verdaderas o falsas? Estos interrogantes me han atormentado durante más de cuarenta años y han sido la fuerza motor detrás de mis esfuerzos continuados de contribuir a esta disciplina.

Como indicas en tu pregunta, mis opiniones han sufrido muchos cambios. En Norma y Acción adopté el punto de vista de que la lógica deóntica se ocupa primariamente de las proposiciones que dicen que tales y cuáles normas existen, pero también refleja las peculiaridades conceptuales de las normas mismas. Esta posición es insatisfactoria, pues convierte a la lógica deóntica en un «matrimonio» entre algo lógico y algo alógico.

Más tarde, en los años setenta y al comienzo de los ochenta, mis puntos de vista cambiaron en forma más radical, acercándose a un «nihilismo lógico» parecido a la posición de Kelsen en su vejez. Puesto que las normas carecen de valores de verdad, no puede haber entre ellas relaciones lógicas genuinas. Esta concepción, sin embargo, ¡tenía que reconciliarse con el hecho de que la lógica deóntica efectivamente existía! Pensé que esto era posible invocando la noción de racionalidad (actividad racional creadora de normas) para explicar la apariencia de las relaciones lógicas entre normas. De esta manera se podía «rescatar» la lógica deóntica 
de la destrucción y justificar los esfuerzos de los lógicos para seguir desarrollándola.

Todavía mantengo fundamentalmente este punto de vista sobre el status lógico de las normas -pero con una modificación importante. Pienso ahora que las relaciones que gobiernan la legislación racional son genuinamente lógicas. Esta concepción tiene afinidades con los esfuerzos de Alchourrón y Martino para desarrollar una lógica sin verdad («logica senza verità»). Lo que hace que la lógica deóntica sea filosóficamente importante es -diría yo- que la lógica tiene efectivamente «un alcance mayor que la verdad». Esta opinión ya la expresé con estas palabras en una de mis primeras publicaciones sobre este tema. Pero lo hice en forma acrítica, sin darme cuenta de que esta tesis requería defensa y justificación elaboradas. Espero que haya logrado entre tanto darle el fundamento filosófico necesario.

Al mismo tiempo, sin embargo, ha ocurrido una nueva radicalización de mis pensamientos. Me he vuelto escéptico respecto del uso de las conectivas proposicionales (palabras tales como "no", “y”, “o”, etc.) tanto para unir formulaciones normativas genuinas, como para enunciar los contenidos de las normas. Si mi crítica está justificada, requerirá un cambio de las concepciones corrientes de cómo ha de ser construido un sistema formal (cálculo) de la lógica deóntica. Queda por ver si los lógicos aceptarán esta idea.

6. ¿En qué sentido la lógica (en sus diferentes ramas) es importante para la filosofia en general y para la filosofía del derecho en particular? Por lo menos desde los tiempos de Frege y Russell la lógica ha desempeñado un papel muy prominente en la filosofía, especialmente en la llamada filosofía analitica, que ha sido muy influyente en este siglo. ¿Piensas que esta situación ha de cambiar en el futuro? ¿Qué piensas de las futuras perspectivas de la filosofia analítica? ¿Hay signos que indican un cambio profundo en el clima filosófico?

-La lógica ha desempeñado un papel central en la filosofía en los últimos cien años. Después de un largo período de desatención e incluso de esterilidad, la lógica experimentó un renacimiento drástico alrededor de 1900, primordialmente gracias a la obra de Frege y Russell. La lógica renacida resultó un instrumento poderoso para la clarificación de las estructuras conceptuales también en otras ramas de la filosofía, en particular en epistemología y filosofía de la ciencia. Russell, cuya participación en el renacimiento de la lógica ha sido crucial, también fue responsable, más que ninguna otra figura individual, por esta «invasión» de la lógica en la filosofía general. Sus pasos fueron seguidos por el joven Wittgenstein, quien, a su vez, desempeñó un papel decisivo en el 
positivismo lógico del Círculo de Viena y su subsiguiente ampliación en el movimiento, conocido como la filosofía analítica, que abarcó a todo el mundo.

No vacilaría en calificar la filosofía analítica como la corriente más poderosa y más característica en la filosofía del siglo veinte. Pero ciertamente vacilaría en pronosticar que esto será así también en el siglo siguiente. Puedo dar dos razones para mis dudas.

La primera tiene que ver con el desarrollo interno de la lógica como disciplina. La lógica en su forma renovada comenzó como investigación sobre los fundamentos de la matemática -y los fundamentos de una materia son en virtud de su naturaleza también incumbencia de los filósofos. Pero como la «crisis de fundamentación» fue superándose gradualmente y dejó de «preocupar» a los filósofos, la lógica tendió a convertirse en una disciplina matemática entre otras. Tiene conexiones estrechas con la ciencia de la computación, siendo el computador mismo un resultado de la lógica pura. Por vía del computador, la lógica encuentra ahora rápidas aplicaciones también en la tecnología electrónica.

Mi segunda razón para el escepticismo tiene una fuente muy distinta. El positivismo lógico y el empirismo lógico, como así también la mayor parte de lo que más tarde se conoció bajo el rótulo de filosofía analítica, estuvieron desde el principio firmemente orientados hacia la ciencia. De esa manera, la filosofía analítica se convirtió en la filosofía par excéllence de una cultura marcada por la ciencia y la tecnología. Cabe decir que el progreso espectacular en esos aspectos de la civilización ha sido la gloria del siglo veinte, pero también cabe decir que la ciencia y la tecnología han problematizado las condiciones económicas, políticas y sociales en la tierra e incluso han creado amenazas para la supervivencia humana. Estos aspectos alarmantes y hasta «apocalípticos» de nuestra cultura no ofrecen obvio material de reflexión para la investigación conceptual del tipo del que la filosofía analítica orientada hacia la ciencia ha llevado a cabo tradicionalmente. Constituyen un desafío, en cambio, para la reflexión sobre problemas de naturaleza ética y también sobre problemas concernientes al hombre y a su destino. Se podría aventurar, tal vez, con cautela, la predicción de que la ética será el centro de la filosofía en el nuevo siglo, así como la lógica lo ha sido en las primeras décadas del presente siglo.

7. Muchos filósofos del derecho, quizá la mayoría, no están ya interesados en la metaética, sino en la ética normativa, esto es, en problemas de valores, por ejemplo, referentes a los derechos humanos, liberalismo, paternalismo, problemas de ética médica 
(aborto, eutanasia, transplantes, etc.). ¿Piensas que tales cuestiones dan lugar a genuinos problemas filosóficos?

-Sí, creo que se trata de genuinos problemas filosóficos. Son en buena medida nuevas formas de viejos, más o menos perennes, problemas. Estos problemas han adquirido de nuevo urgencia debido a los cambios en la situación socio-política global y también a las repercusiones de la tecnología industrial sobre el medio ambiente. La «crisis cultural» que ha sido un fenómeno más o menos permanente desde el Renacimiento y la Reforma ha asumido de repente formas dramáticas, haciendo problemático el futuro de la humanidad.

Sin embargo, aunque sean genuinamente «filosóficos», los problemas que mencionas no pueden ser enfocados fácilmente con los «métodos» que han sido comunes en la llamada filosofía analítica. Creo que estos problemas requieren en parte nuevas técnicas conceptuales para su tratamiento exitoso, y a falta de tales herramientas la reaparición de esos problemas puede fácilmente aparecer como un retroceso hacia etapas ya superadas en el desarrollo histórico de la filosofía.

8. El cognoscitivismo ético parece ser la tendencia dominante en nuestros días; muchos autores contemporáneos que escriben sobre temas éticos y políticos consideran que los juicios de valor son (objetivamente) verdaderos o falsos. ¿Cuál es tu opinión sobre el papel desempeñado por la verdad en este campo?

-Debo confesar que observo con alguna desconfianza el surgimiento del cognitivismo en la teoría de los valores, así como también el renacimiento de la ética normativa y diversas doctrinas de derecho natural. Como ya lo he indicado, estos «renacimientos» han ocurrido como respuesta a problemas filosóficos reales, pero no estoy seguro de que representen «intentos nuevos» que son necesarios para tratar los problemas en el nuevo marco cultural en el cual aparecen ahora. El destierro no cognitivista de las normas y de los valores del campo de la ciencia y de la argumentación racional puede haber sido apresurado y necesita reconsideración. Pero las herramientas filosóficas para hacer frente a esta necesidad están todavía notoriamente ausentes.

Tal vez pueda referirme a la lógica deóntica para ilustrar este punto. Como hemos visto, la lógica deóntica suscita problemas que penetran profundamente en los fundamentos filosóficos del pensamiento lógico. Las respuestas, si tengo razón, modificarán las concepciones tradicionales de lo que es la lógica y mostrarán que la lógica como estudio de lo racional trasciende los límites de lo verdadero y lo falso. Una modificación similar puede ser necesaria en la teoría de los valores. Pero hay que hacerla todavía. 
9. Tú mismo has escrito bastante sobre problemas políticos y éticos; ¿consideras tus opiniones como objetivamente verdaderas o como meras expresiones de preferencias personales y/ o actitudes emocionales?

-Te refieres posiblemente a pensamientos que he expresado -particularmente en años recientes- acerca del impacto de la ciencia y de la tecnología sobre la vida moderna y acerca de las amenazas al futuro del hombre provenientes del desequilibrio global, político y social y el desastre ambiental. Preferiría considerar estos pensamientos como una filosofía de naturaleza visionaria. No son en ningún sentido directo verdaderos o falsos. Pero tampoco son «meras expresiones de actitudes emocionales». Son esfuerzos por entender el significado de los hechos que tenemos constantemente presentes debido tanto a la observación personal, como a los medios de comunicación y que a la gente reflexiva causan perplejidad y angustia. Tales esfuerzos no son tanto una pesquisa de información y conocimiento, como una búsqueda de orientación en el mundo, de una perspectiva que nos permita ver las cosas en sus proporciones correctas y, ocasionalmente, también valorarlas como buenas o malas.

10. Muchos filósofos del derecho interesados en la teoría de la argumentación opinan que las reglas lógicas son demasiado estrechas o demasiado estrictas para ser capaces de dar cuenta de muchos argumentos «sanos» o «razonables», especialmente en los contextos jurídicos, por ejemplo, argumentos usados para la justificación de las decisiones judiciales. De ahí que traten de elaborar reglas nuevas y más liberales para el control racional de tales argumentos; esto parece implicar un concepto más amplio de racionalidad ( LLo racional como razonable» es el título de un libro recientemente aparecido de un filósofo del derecho que pertenece a esa tendencia). Un desarrollo similar puede observarse entre los que trabajan en el campo de la inteligencia artificial, quienes han elaborado diversos sistemas de lógicas no monotónicas. ¿Qué nos puedes decir sobre estos desarrollos?

-Posiblemente no conozca esos desarrollos suficientemente bien como para tener una opinión definida sobre ellos. Ellos también son síntomas de una tendencia a trascender los límites tradicionales de la lógica en los intentos de dar cuenta de la argumentación jurídica. Pero al relajar las pautas de racionalidad en lugar de abandonar la exigencia de valores de verdad, tales desarrollos pueden correr el riesgo de relajar también las pautas de rigor y precisión que me parece esencial mantener. Tal vez yo sea «anticuado», pero no puedo evitar la impresión de que el pensamiento analítico en la filosofía en general y no menos en la 
filosofía jurídica y moral ha perdido algo de sobriedad y exigencia de claridad que era su característica a comienzos y mediados del siglo. El filósofo analítico a quien aprendí a admirar como parangón de honestidad intelectual era G. E. Moore. Vale la pena todavía seguir su ejemplo. 